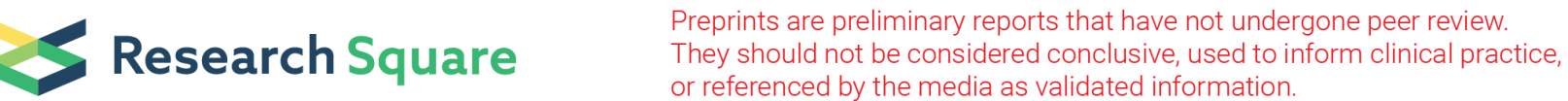

\section{Correlation between kinematic sagittal parameters of the cervical lordosis or head posture and disc degeneration in patients with posterior neck pain: retrospective cross-sectional study}

Hyo Jeong Lee

Gangnam Severance Hospital https://orcid.org/0000-0001-8300-3407

Dae Geun Jeon

Gangnam Severance Hospital

Jinyoung Park

Gangnam Severance Hospital

Jung Hyun Park ( $\square$ rmpjh@yuhs.ac)

Yonsei University https://orcid.org/0000-0003-3262-7476

Research article

Keywords: Cervical Vertebrae: Intervertebral Disc Degeneration: Kyphosis: Lordosis: Neck pain

Posted Date: May 8th, 2020

DOI: https://doi.org/10.21203/rs.3.rs-26105/v1

License: (c) (i) This work is licensed under a Creative Commons Attribution 4.0 International License.

Read Full License 


\section{Abstract \\ Background}

The aim of this study was to examine degrees of the cervical disc degeneration and the parameters of cervical sagittal balance in plain radiographs, representing cervical lordosis or head posture in subjects with posterior neck pain.

\section{Methods}

This study was a retrospective cross-sectional study that analyzed 113 patients with posterior neck pain with or without radiating pain. The kinematic sagittal parameters of cervical radiographs were obtained at the occipito-cervical (O-C2) angle, sagittal Cobb's angles of $\mathrm{C} 1-\mathrm{C} 2, \mathrm{C} 2-\mathrm{C} 7$, and sagittal vertical axis (SVA) of $\mathrm{C} 1-\mathrm{C} 7$ and $\mathrm{C} 2-\mathrm{C} 7$. Cervical disc degeneration was evaluated using the sum of Pfirrmann grades and total modified Matsumoto scores calculated from magnetic resonance images (MRI) of the cervical spine. Pearson's correlation analysis was conducted to evaluate the relationship of these parameters and a linear regression method was used to determine associations between sagittal cervical alignment and disc degeneration.

\section{Results}

A significant positive correlation was found for the $\mathrm{C} 2-\mathrm{C} 7$ angle using the sum of the Pfirrmann grades and total modified Matsumoto scores. The O-C2 angle was negatively correlated with the sum of the Pfirrmann grades and total modified Matsumoto scores. The C1-C2 angle was also negatively correlated with the sum of the Pfirrmann grades. No significant relationship was found between the cervical SVA and cervical disc degeneration.

\section{Conclusions}

The sagittal cervical parameters representing cervical kyphosis and jaw lifting posture, were found to be significantly correlated with the degree of cervical disc degeneration. These findings suggest that the loss of the natural sagittal lordosis of the cervical spine may contribute to the progression of disc degeneration, rather than the forward head posture.

\section{Background}

Loss of cervical lordosis is the most common disorder of sagittal cervical balance.[30, 33] Although the sagittal alignment of the cervical vertebrae can vary with age and sex,[8,30] the natural sagittal curve of the cervical spine is known to have a lordosis $[7,12,19]$. Harrison et al. reported a mean C2-C7 lordotic angle of $-26.89^{\circ} \pm 9.72^{\circ}$ in 72 healthy participants.[12] Liu et al. demonstrated a mean C2-C7 lordotic 
angle of $-21.40^{\circ} \pm 12.15^{\circ}$ in 212 asymptomatic volunteers [19]. The estimated prevalence of loss of cervical lordosis in patients with posterior neck pain is approximately $42 \%$.[13] Recently, several studies have demonstrated that a spectrum of cervical disorders are associated with a loss of cervical lordosis, i.e. kyphosis.[10, 16, 30, 32] A cross-sectional study revealed that decreasing natural cervical lordosis was correlated with increasing Neck Disability Index scores in pre-operative subjects.[14] Another prospective cohort study reported that patients with higher preoperative lordotic angles showed better outcomes than those with a kyphotic alignment.[32] Some studies have shown negative consequences of cervical malalignment on the health-related quality of life.[1, 2, 30]

Forward head posture (FHP) is common in sagittal cervical imbalance in patients with symptomatic neck pain. FHP is usually defined as an increased sagittal vertical axis (SVA) in which the head is shifted anteriorly to the shoulder plane compared to the neutral posture. The normal physiological C2-C7 SVA is estimated to be $16.8 \pm 11.2 \mathrm{~mm}$ in asymptomatic subjects.[11] Several studies have found that an increased SVA value is related to clinical symptoms.[3, 34]

The majority of research on sagittal cervical balance has been focused on analyzing radiographs of the cervical spine and comparing them with clinical symptoms, $[3,17,30]$ whereas few studies have focused on the relationship between cervical sagittal alignment and disc degeneration as seen on magnetic resonance imaging (MRI). Previously, the progression of cervical disc degeneration was higher in the nonlordotic group than in the lordotic group; however, the study only analyzed the C2-C7 Cobb's angle regardless consideration of the other sagittal variables, such as SVA or the occipito-cervical angle.[26]

The results of this study may serve as investigation of the relationship between cervical disc degeneration as assessed using MRI and parameters of sagittal cervical balance in plain radiographs, representing cervical lordosis or FHP in patients with posterior neck pain.

\section{Methods}

\section{Subjects}

Four hundred and twenty-one patients with posterior neck pain who visited the spine center of a university hospital in a metropolitan area were retrospectively analyzed. Only subjects with both cervical spine radiographs and cervical MRls were included. The exclusion criteria were as follows: history of cervical spinal surgery or trauma, age under nineteen years, symptoms or signs of inflammatory back pain, such as ankylosing spondylitis, imaging evidence of concurrent myelopathy, and spine fracture. A total of 113 patients were included in our study population.

\section{Measurements}

\subsection{Kinematic parameters of cervical spine using plain radiographs}

All cervical plain radiographs were reviewed and analyzed using a picture archiving and communication system. Using plain lateral cervical radiographs, the following parameters were measured: occipito- 
cervical angulation (O-C2 angle), sagittal Cobb's angles of the C1-C2, C2-C7 (C1-C2 angle, C2-C7 angle), and SVA of C1-C7, C2-C7 (C1-C7 SVA, C2-C7 SVA, Fig. 1).

\subsection{Cervical disc degeneration measured by MRIs}

3.0-T cervical MRIs (Discovery MR750; GE Healthcare, Milwaukee, WI) were performed to evaluate disc degeneration. Sagittal and axial T2-weighted MR imaging was performed for each cervical level. The severity of disc degeneration was assessed according to the Pfirrmann grades [28] and modified Matsumoto classification scores [25]. Each grade and score of the cervical levels from C2-C3 to C6-C7 was measured, and summation analysis was performed. Pfirrmann grades are used to evaluate degenerated intervertebral discs for (i) distinction of the annulus and the nucleus, (ii) disc structure, (iii) signal intensity of discs, and (iv) height of discs by using T2-weighted mid-sagittal images.[28] The modified Matsumoto classification scores assess disc degeneration for (i) change in the signal of the disc, (ii) posterior protrusion of the disc, and (iii) narrowing of disc space in T2-weighted axial and midsagittal images.[25]

\subsection{Lordotic and Non-lordotic groups}

To identify the specific correlation of kinematic sagittal parameters with cervical disc degeneration, the patients were divided into two groups (lordotic group and non-lordotic group), according to the C2-C7 Cobb angle observed on cervical plain radiographs. We set the cutoff of the $\mathrm{C} 2-\mathrm{C} 7$ lordotic angle as $-17.17^{\circ}$, based on the study by Harrison et al.[12]

\section{Statistical analysis}

The comparisons between groups were performed using an independent t-test. The reliability of the measurements was assessed by examining the intra-observer and inter-observer reliability with intra-class correlation coefficients. The correlations between cervical parameters were determined using a Pearson's test. A linear regression method was used to determine associations between the parameters of sagittal cervical alignment and the degree of cervical disc degeneration. All statistical analyses were performed with SAS version 9.3 (SAS Institute, Cary, NC).

\section{Ethics statement}

The present study protocol was reviewed and approved by the Institutional Review Board of Gangnam Severance Hospital, Yonsei University Medical College (\# 2016-0558-001).

\section{Results}

\section{Basic characteristics of the two groups}

This study included a total of 113 patients ( 55 males, 58 female). The baseline characteristics of the participants are summarized in Table 1. Twenty-six patients (10 males, 16 female) were classified into 
the lordotic group, and 87 patients (45 males, 42 female) were classified into the non-lordotic group. There were no statistical differences in age and sex between the two groups.

\section{Reliability Analysis}

The intra-rater and inter-rater observer agreements for cervical parameters and disc degeneration were analyzed (Table 2). In both intra-rater and inter-rater studies, good agreements were found, with $\mathrm{k}$ values ranging from 0.72 to 0.91 .

\section{Analysis of cervical angles}

The $\mathrm{C} 2-\mathrm{C} 7$ angle was significantly correlated with the $0-\mathrm{C} 2$ and $\mathrm{C} 1-\mathrm{C} 2$ angles. The $\mathrm{O}-\mathrm{C} 2$ angle was significantly correlated with the C1-C2 angle, C1-C7 SVA and C2-C7 SVA. The C1-C7 SVA and C2-C7 SVA were correlated with the $\mathrm{C} 1-\mathrm{C} 2$ angle (Table 3 ). There was no significant correlation between age and any measured radiographic parameter.

\section{Analysis of cervical disc degeneration by Pfirmann grades}

The degree of disc degeneration was assessed using Pfirrmann grades at each level. In the assessment of disc degeneration according to Pfirrmann grades, grade I was most commonly observed at the C2-C3 level. Grade V was more common at the C5-C6 level than at any other level (Fig. 2).

\section{Correlation between kinematic parameters of the cervical spine and disc degeneration}

\subsection{Cervical angles and disc degeneration}

Using a multivariate regression analysis adjusted for age, the $\mathrm{C} 2-\mathrm{C} 7$ angle revealed a significant positive correlation with both the sum of Pfirrmann grades $(r=0.33, P<0.005)$ and the total modified Matsumoto scores $(r=0.27, P<0.005)$, although age was not a co-linear factor (Fig. 3a, 3b). There was a significant negative correlation between the 0-C2 angle, and both the sum of Pfirrmann grades $(r=-0.16, P=0.005)$ and the total modified Matsumoto scores $(r=-0.11, P=0.02)$ (Fig. 3c, d). The C1-C2 angle was negatively correlated with the Pfirrmann grades $(r=-0.15, P=0.018)$ (Fig. 3e).

\subsection{SVA and disc degeneration}

The C2-C7 SVA and the C1-C7 SVA did not reveal a correlation with the sum of Pfirrmann grades or the total modified Matsumoto scores (Table 4). In both subgroups (lordotic and non-lordotic groups), the SVA had no significant correlation with the Pfirrmann grades or the total modified Matsumoto scores (Table 4).

\section{Discussion}

The cervical spine naturally maintains a lordotic curvature to compensate for the thoracic kyphotic curvature.[8] As the loss of cervical lordosis progresses, the deformity also tends to progress rapidly by 
producing abnormal forces to the head and neck. $[2,30]$ Even with mild sagittal imbalance, detrimental symptoms can develop, which worsen with sagittal imbalance progression.[9] The vertebral disc is designed to maintain an isotropic form by transmitting axial load uniformly across the disc and vertebral endplate.[22, 23] In cervical spinal positions, such as extension, flexion, or lateral bending, the load of the disc is transmitted uniformly over the endplates.[23] Loss of cervical lordosis may alter this isotropic nature of disc loading and consequently contribute to continuous irregular loading, which accelerates disc degeneration. $[23,31]$ This degeneration can be aggravated by normal aging, calcification of the endplate, or decreased peripheral blood supply.[5] Abnormally increased mechanical pressure has also been shown to reduce the nutritional support of the disc and lead to disc degeneration.[29] Our results demonstrate a correlation between loss of cervical lordosis and cervical disc degeneration. In this study, cervical disc degeneration was evaluated using both Pfirrmann grades and the modified Matsumoto scoring system, whereas most previous studies have only used either of them.[4, 15,25,26] Pfirrmann grading assesses the homogeneity of disc structure and includes a distinction between the annulus and nucleus, whereas the modified Matsumoto scoring system considers the degree of the posterior disc protrusion and narrowing of disc space without considering the homogeneity of the disc. This difference in the evaluation criteria may explain the different relationship between the $\mathrm{C} 1-\mathrm{C} 2$ angle and disc degeneration, which the $\mathrm{C} 1-\mathrm{C} 2$ angle is only correlated with the Pfirrmann grades.

Changes in sagittal cervical alignment, such as FHP, may cause or result in adaptive mechanisms to global alignment change, which affects all spinal levels (including the cervical, thoracic, and lumbar regions).[18, 30] Contractions of the neck muscles due to vestibulocollic or cervicocolic reflexes induce anterior shifting of the head/neck center of gravity, resulting in a change in the spinal alignment.[27, 36] These reflexes cause cervical muscle spasm, representing shortening of the posterior neck extensor muscles and the tightening of the anterior neck muscles, which may increase the SVA.[6] Previous studies have shown that a larger C2-C7 SVA is related to higher Neck Disability Index scores [35] and demonstrated a correlation between the C2-C7 SVA and the C1-C2 angle.[35] The results of this study also showed that the C2-C7 SVA was significantly correlated with the 0-C2 angle and the C1-C2 angle. However, to date, the clinical consequences of increased cervical SVA on cervical disc degeneration have not been described. In this study, the change in SVA was not correlated with cervical disc degeneration. Both in the lordotic and non-lordotic groups, the SVA was not correlated with cervical disc degeneration. These findings indicate that the SVA, which has been suggested to be related to FHP in previous studies, has little effect on disc degeneration. Cervical disc degeneration progressing with normal aging could be aggravated by the loss of natural sagittal angles rather than increased cervical SVA. Recently, one study showed significant correlation between cervical lordosis and C2-C7 SVA in asymptomatic Chinese population.[37] In this study, there was no significant correlation between C2-C7 angle and C2-C7 SVA. This may mean that the rate of disc degeneration is greater than that of FHP when clinical symptoms occur.

The optimal position and angle of the occipital bone and the cervical axis have been topics of discussion. $[20,21,24]$ In this study, there was a negative correlation between the $0-\mathrm{C} 2$ and $\mathrm{C} 1-\mathrm{C} 2$ angle and the $\mathrm{C} 2-$ $\mathrm{C} 7$ angle, as well as a significant correlation with the SVA. These results suggest a correlation between 
the occipital-cervical axis, cervical kyphosis, and FHP. There was a significant correlation between the occipito-cervical angle and cervical disc degeneration in this study. A recent cohort study showed that an increased occipito-cervical angle may result in large biomechanical stress on the adjacent structures or deformation of cervical alignment.[21] A previous study has shown that the loss of the natural C2-C7 angle facilitates cervical disc degeneration.[26] In addition, our findings suggest that a more negative occipito-cervical angle may accelerate disc degeneration. In summary, the SVA, the occipito-cervical angle, and the loss of cervical lordosis, expressed easily as the "forward head posture", "the jaw lifting posture" and "the cervical kyphosis", were correlated with each other. Also, only the latter two, the jaw lifting posture and the cervical kyphosis had were correlated with disc degeneration. Although the causeand-effect relationship is unknown, it can be interpreted that FHP worsens the jaw lifting posture and cervical kyphosis, which may cause disc degeneration.

This study has some limitations. The pathophysiological mechanism of disc degeneration due to the loss of cervical lordosis remains unknown. As the analyses were cross-sectional, determining a cause-andeffect relationship is difficult. Furthermore, neck pain was not classified as causal factor in this study. As cervical disc degeneration progresses, neck pain or uneven loading to the cervical disc can induce deformity of the sagittal alignments, including both cervical and occipito-cervical angles. Long-term changes in the sagittal cervical parameters and disc degeneration were also not evaluated. Prospective longitudinal studies with long-term follow-up are necessary to investigate the clinical implications and the interactions between the alignment of cervical spines and the discs. Finally, as we did not include an asymptomatic group of participants, the results may not be generalizable to whole populations. Future long-term longitudinal studies in a general asymptomatic population are needed.

\section{Conclusions}

This study showed that sagittal cervical parameters, such as the $\mathrm{C} 2-\mathrm{C} 7$ angle, $\mathrm{O}-\mathrm{C} 2$ angle, and $\mathrm{C} 1-\mathrm{C} 2$ angle, were correlated with the degree of cervical disc degeneration in patients with posterior neck pain. However, there was no significant correlation between the SVA and disc degeneration. These results revealed that loss of the natural cervical lordosis is correlated substantially with cervical disc degeneration, rather than the FHP.

\section{Abbreviations}

FHP: Forward Head Posture; SVA: Sagittal Vertical Axis; MRI: Magnetic Resonance Images

\section{Declarations}

\section{Author Contributions}

DG collected and analyzed the data regarding cervical spine in images. JY performed the data curation and edited the writing. $\mathrm{HJ}$ was a major contributor in writing this manuscript and $\mathrm{JH}$ conceptualized the 
topic and supervised the study. All authors read and approved the final manuscript.

\section{Funding}

Not applicable.

\section{Availability of data and materials}

We declare that the materials described in the manuscript will be freely available to all scientists for noncommercial purposes.

\section{Ethics approval and consent to participate}

Ethics approval was provided by Gangnam Severance Hospital, Yonsei University Medical College and the consent of patients was not applicable in this study.

\section{Consent for publication}

Not applicable.

\section{Competing interests}

All the authors in this manuscript have read and approved the final version submitted, and no author has a conflict of interest in this submission.

\section{Acknowledgements}

Not applicable.

\section{References}

1. Adams MA, Hutton WC. The effect of posture on the role of the apophysial joints in resisting intervertebral compressive forces. J Bone Joint Surg Br. 1980;62:358-62.

2. Ao S, Liu Y, Wang Y, Zhang H, Leng H. Cervical kyphosis in asymptomatic populations: incidence, risk factors, and its relationship with health-related quality of life. J Orthop Surg Res. 2019;14:322.

3. Bao H, Varghese J, Lafage R, Liabaud B, Diebo BG, Ramchandran S, et al. Principal radiographic characteristics for cervical spinal deformity: a health-related quality of life analysis. The Spine Journal. 2016;16:282.

4. Bao H, Zhu F, Liu Z, Zhu Z, He S, Ding Y, et al. Coronal curvature and spinal imbalance in degenerative lumbar scoliosis: disc degeneration is associated. Spine (Phila Pa 1976). 2014;39:E1441-7.

5. Buckwalter JA. Aging and degeneration of the human intervertebral disc. Spine (Phila Pa 1976). 1995;20:1307-14. 
6. Fernandez-de-las-Penas C, Alonso-Blanco C, Cuadrado ML, Pareja JA. Neck mobility and forward head posture are not related to headache parameters in chronic tension-type headache. Cephalalgia. 2007;27:158-64.

7. Gangnet N, Pomero V, Dumas R, Skalli W, Vital JM. Variability of the spine and pelvis location with respect to the gravity line: a three-dimensional stereoradiographic study using a force platform. Surg Radiol Anat. 2003;25:424-33.

8. Gay RE. The curve of the cervical spine: variations and significance. J Manipulative Physiol Ther. 1993;16:591-4.

9. Glassman SD, Bridwell K, Dimar JR, Horton W, Berven S, Schwab F. The impact of positive sagittal balance in adult spinal deformity. Spine (Phila Pa 1976. 2005;30:2024-9.

10. Gum JL, Glassman SD, Douglas LR, Carreon LY. Correlation between cervical spine sagittal alignment and clinical outcome after anterior cervical discectomy and fusion. Am J Orthop (Belle Mead NJ). 2012;41:E81-4.

11. Hardacker JW, Shuford RF, Capicotto PN, Pryor PW. Radiographic standing cervical segmental alignment in adult volunteers without neck symptoms. Spine. 1997;22:1472-9.

12. Harrison DD, Harrison DE, Janik TJ, Cailliet R, Ferrantelli JR, Haas JW, et al. Modeling of the sagittal cervical spine as a method to discriminate hypolordosis: results of elliptical and circular modeling in 72 asymptomatic subjects, 52 acute neck pain subjects, and 70 chronic neck pain subjects. Spine (Phila Pa 1976). 2004;29:2485-92.

13. Helliwell PS, Evans PF, Wright V. The straight cervical spine: does it indicate muscle spasm? J Bone Joint Surg Br. 1994;76:103-6.

14. Iyer S, Nemani VM, Nguyen J, Elysee J, Burapachaisri A, Ames CP, et al. Impact of Cervical Sagittal Alignment Parameters on Neck Disability. Spine (Phila Pa 1976). 2016;41:371-7.

15. Keorochana G, Taghavi CE, Lee KB, Yoo JH, Liao JC, Fei Z, et al. Effect of sagittal alignment on kinematic changes and degree of disc degeneration in the lumbar spine: an analysis using positional MRI. Spine (Phila Pa 1976). 2011;36:893-8.

16. Kim JH, Park JY, Yi S, Kim KH, Kuh SU, Chin DK, et al. Anterior cervical discectomy and fusion alters whole-spine sagittal alignment. 2015;56:1060-70.

17. Le Huec J, Demezon H, Aunoble S. Sagittal parameters of global cervical balance using EOS imaging: normative values from a prospective cohort of asymptomatic volunteers. Eur Spine J. 2015;24:63-71.

18. Lee SH, Kim KT, Seo EM, Suk KS, Kwack YH, Son ES. The influence of thoracic inlet alignment on the craniocervical sagittal balance in asymptomatic adults. J Spinal Disord Tech. 2012;25:E41-7.

19. Liu B, Wu B, Van Hoof T, Okito JP, Liu Z, Zeng Z. Are the standard parameters of cervical spine alignment and range of motion related to age, sex, and cervical disc degeneration? J Neurosurg Spine. 2015;23:274-9.

20. Matsunaga S, Onishi T, Sakou T. Significance of occipitoaxial angle in subaxial lesion after occipitocervical fusion. Spine (Phila Pa 1976). 2001;26:161-5. 
21. Maulucci CM, Ghobrial GM, Sharan AD, Harrop JS, Jallo JI, Vaccaro AR, et al. Correlation of posterior occipitocervical angle and surgical outcomes for occipitocervical fusion. Evid Based Spine Care J. 2014;5:163-5.

22. McNally DS, Adams MA. Internal intervertebral disc mechanics as revealed by stress profilometry. Spine (Phila Pa 1976). 1992;17:66-73.

23. Mulholland RC. The myth of lumbar instability: the importance of abnormal loading as a cause of low back pain. Eur Spine J. 2008;17:619-25.

24. Nunez-Pereira S, Hitzl W, Bullmann V, Meier O, Koller H. Sagittal balance of the cervical spine: an analysis of occipitocervical and spinopelvic interdependence, with C-7 slope as a marker of cervical and spinopelvic alignment. J Neurosurg Spine. 2015;23:16-23.

25. Okada E, Matsumoto M, Fujiwara H, Toyama Y. Disc degeneration of cerith lumbar disc herniatiovical spine on MRI in patients wn: comparison study with asymptomatic volunteers. Eur Spine J. 2011;20:585-91.

26. Okada E, Matsumoto $M$, Ichihara D, Chiba K, Toyama Y, Fujiwara H, et al. Does the sagittal alignment of the cervical spine have an impact on disk degeneration? Minimum 10-year follow-up of asymptomatic volunteers. Eur Spine J. 2009;18:1644-51.

27. Peterson BW, Goldberg J, Bilotto G, Fuller JH. Cervicocollic reflex: its dynamic properties and interaction with vestibular reflexes. J Neurophysiol. 1985;54:90-109.

28. Pfirrmann CW, Metzdorf A, Zanetti M, Hodler J, Boos N. Magnetic resonance classification of lumbar intervertebral disc degeneration. Spine (Phila Pa 1976). 2001;26:1873-8.

29. Rihn JA, Lawrence J, Gates C, Harris E, Hilibrand AS. Adjacent segment disease after cervical spine fusion. Instr Course Lect. 2009;58:747-56.

30. Scheer JK, Tang JA, Smith JS, Acosta FL Jr, Protopsaltis TS, Blondel B, et al. Cervical spine alignment, sagittal deformity, and clinical implications: a review. J Neurosurg Spine. 2013;19:14159.

31. Sengupta DK, Fan $\mathrm{H}$. The basis of mechanical instability in degenerative disc disease: a cadaveric study of abnormal motion versus load distribution. Spine (Phila Pa 1976). 2014;39:1032-43.

32. Shamji MF, Mohanty C, Massicotte EM, Fehlings MG. The Association of Cervical Spine Alignment with Neurologic Recovery in a Prospective Cohort of Patients with Surgical Myelopathy: Analysis of a Series of 124 Cases. World Neurosurg. 2016;86:112-9.

33. Steinmetz MP, Stewart TJ, Kager CD, Benzel EC, Vaccaro AR. Cervical deformity correction. Neurosurgery. 2007;60:90-7.

34. Tang JA, Scheer JK, Smith JS, Deviren V, Bess S, Hart RA, et al. The impact of standing regional cervical sagittal alignment on outcomes in posterior cervical fusion surgery. Neurosurgery. 2012;76:14-21.

35. Tang JA, Scheer JK, Smith JS, Deviren V, Bess S, Hart RA, et al. The Impact of Standing Regional Cervical Sagittal Alignment on Outcomes in Posterior Cervical Fusion Surgery. Neurosurgery. 2015;76:14-s21. 
36. Wilson VJ, Schor RH. The neural substrate of the vestibulocollic reflex. What needs to be learned. Exp Brain Res. 1999;129:483-93.
37. Zhu Y, An Z, Zhang Y, Wei H, Dong L. Predictive formula of cervical lordosis in asymptomatic young population. J Orthop Surg Res. 2020;15:2.

\section{Tables}

Table 1 Baseline demographic characteristics of participants

\begin{tabular}{|c|c|c|c|}
\hline & $\begin{array}{l}\text { Total participants } \\
\qquad(\mathrm{n}=113)\end{array}$ & $\begin{array}{l}\text { Lordotic group } \\
\qquad(\mathrm{n}=26)\end{array}$ & $\begin{array}{l}\text { Non-lordotic group } \\
\qquad(\mathrm{n}=87)\end{array}$ \\
\hline Age (years) & $51.3 \pm 10.1$ & $52.4 \pm 11.1$ & $51.0 \pm 9.8$ \\
\hline Sex & $55(48.6 \%) / 58(51.3 \%)$ & $10(38.4 \%) / 16(61.6 \%)$ & $45(51.7 \%) / 42(48.3 \%)$ \\
\hline \multicolumn{4}{|l|}{ male / female, n (\%) } \\
\hline \multicolumn{4}{|l|}{ Sagittal parameters } \\
\hline O-C2 angle $\left({ }^{\circ}\right)$ & $-23.36 \pm 7.40$ & $-18.08 \pm 5.85^{*}$ & $-24.94 \pm 7.10$ \\
\hline C1-C2 angle ( $\left(^{\circ}\right)$ & $-26.27 \pm 6.53$ & $-22.4 \pm 6.58^{*}$ & $-27.42 \pm 6.09$ \\
\hline C2-C7 angle $\left({ }^{\circ}\right)$ & $-9.97 \pm 10.00$ & $-21.48 \pm 5.78^{*}$ & $-6.53 \pm 8.29$ \\
\hline SVA of C1-C7 (mm) & $26.83 \pm 11.65$ & $22.61 \pm 8.76^{*}$ & $28.09 \pm 12.15$ \\
\hline SVA of C2-C7 (mm) & $18.23 \pm 9.43$ & $16.03 \pm 7.59$ & $18.88 \pm 9.85$ \\
\hline \multicolumn{4}{|l|}{ Cervical disc degeneration } \\
\hline Sum of Pfirrmann grades & $14.7 \pm 4.7$ & $11.0 \pm 4.6^{*}$ & $15.9 \pm 4.2$ \\
\hline Total modified Matsumoto scores & $13.1 \pm 4.3$ & $9.92 \pm 3.7^{*}$ & $14.0 \pm 4.0$ \\
\hline
\end{tabular}

Values are presented as mean \pm standard deviation.

SVA: sagittal vertical axis

${ }^{*} P<0.05$, significant difference compared with the non-lordotic group

Table 2 Intra-rater and inter-rater reliability for all subjects 


\begin{tabular}{lcc}
\hline & Intra-rater reliability & Inter-rater reliability \\
\hline O-C2 angle & 0.89 & 0.81 \\
C1-C2 angle & 0.72 & 0.78 \\
C2-C7 angle & 0.88 & 0.85 \\
C1-C7 SVA & 0.89 & 0.87 \\
C2-C7 SVA & 0.85 & 0.91 \\
Sum of Pfirrmann grades & 0.88 & 0.85 \\
Total modified Matsumoto scores & 0.90 & 0.86 \\
\hline
\end{tabular}

SVA: sagittal vertical axis

Table 3 Correlation among the cervical sagittal parameters

\begin{tabular}{lcccc}
\hline & C2-C7 angle & O-C2 angle & C1-C2 angle & C1-C7 SVA \\
\hline O-C2 angle & $-0.445^{* *}$ & & & \\
C1-C2 angle & $-0.322^{* *}$ & $0.724^{* *}$ & & \\
C1-C7 SVA & 0.294 & $-0.560^{* *}$ & $-0.339^{* *}$ & \\
C2-C7 SVA & 0.198 & $-0.505^{* *}$ & $-0.302^{* *}$ & $0.974^{* *}$ \\
\hline
\end{tabular}

${ }^{*}$ Correlation was significant at the $P<0.05$ level. ${ }^{* *} P<0.01$ level

SVA: sagittal vertical axis

Table 4 Correlation between sagittal cervical vertical axis and degree of cervical disc degeneration 


\begin{tabular}{|c|c|c|c|c|c|c|c|}
\hline & & \multicolumn{2}{|c|}{$\begin{array}{l}\text { Total participants } \\
\qquad(\mathrm{n}=113)\end{array}$} & \multicolumn{2}{|c|}{$\begin{array}{l}\text { Lordotic group } \\
\qquad(\mathrm{n}=26)\end{array}$} & \multicolumn{2}{|c|}{$\begin{array}{l}\text { Non-lordotic group } \\
\qquad(\mathrm{n}=87)\end{array}$} \\
\hline & & C1-C7 SVA & C2-C7 SVA & C1-C7 SVA & C2-C7 SVA & C1-C7 SVA & C2-C7 SVA \\
\hline \multirow[t]{2}{*}{ Sum of Pfirrmann grades } & Coefficient & 0.064 & 0.063 & -0.027 & -0.006 & 0.038 & 0.042 \\
\hline & $P$ & 0.088 & 0.18 & 0.837 & 0.960 & 0.301 & 0.347 \\
\hline \multirow[t]{2}{*}{ Total modified Matsumoto scores } & Coefficient & 0.049 & 0.044 & 0.017 & 0.013 & 0.020 & 0.022 \\
\hline & $P$ & 0.139 & 0.281 & 0.821 & 0.881 & 0.565 & 0.609 \\
\hline
\end{tabular}

SVA: sagittal vertical axis

\section{Figures}




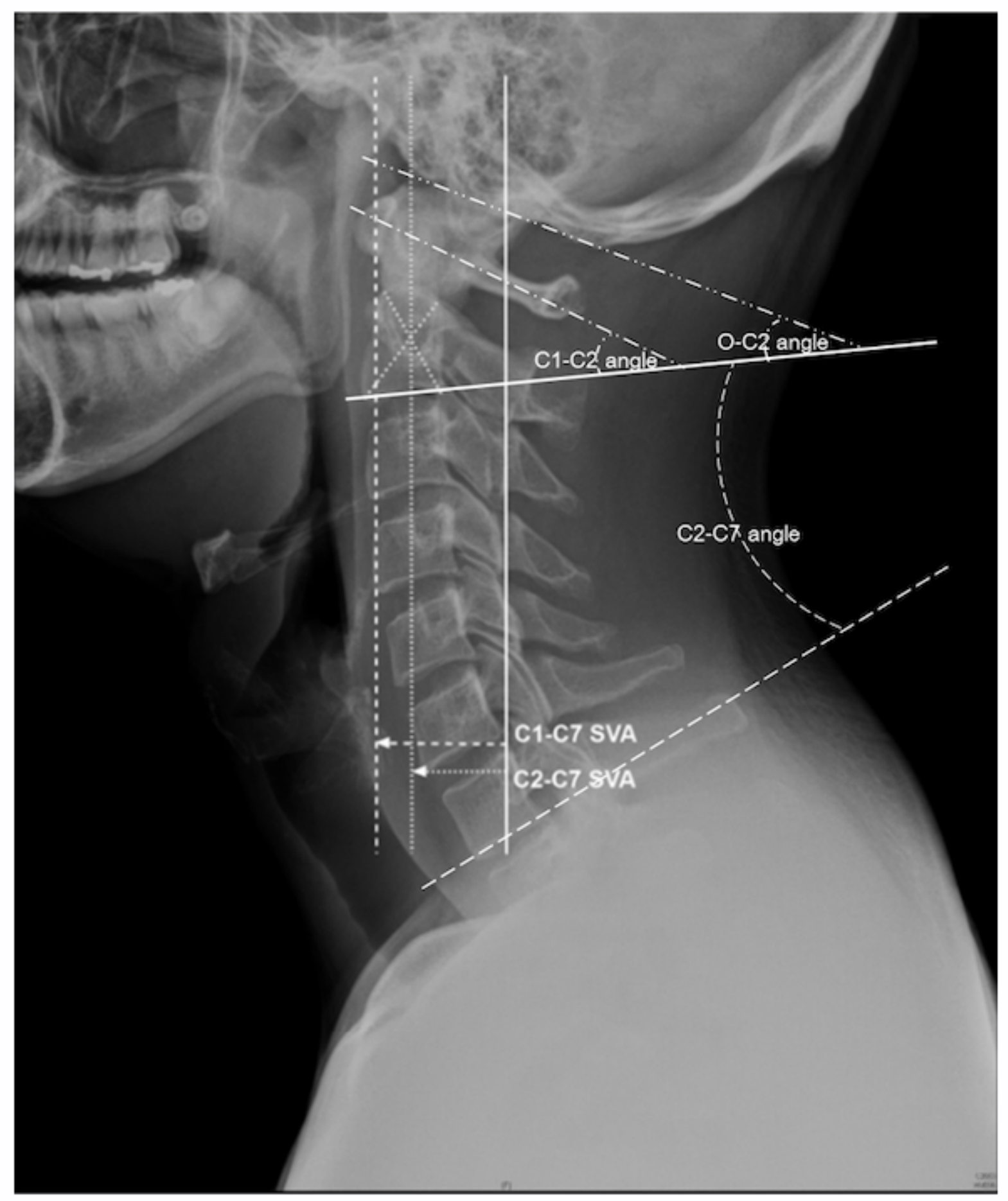

Figure 1

Parameters of sagittal cervical alignment on plain radiographs. O-C2 angle, angle between the McGregor line and the lower endplate of $\mathrm{C} 2$; $\mathrm{C} 1-\mathrm{C} 2$ angle, angle between a line connecting the anterior tubercle to the posterior margin of the $\mathrm{C} 1$ spinous process and the lower endplate of $\mathrm{C} 2 ; \mathrm{C} 2-\mathrm{C} 7$ angle, angle between the lower endplate of C2 and C7 determined with Cobb's method; C1-C7 SVA, distance between the plumb line from the anterior arch of $\mathrm{C} 1$ and the posterior-superior corner of $\mathrm{C} 7 ; \mathrm{C} 2-\mathrm{C} 7 \mathrm{SVA}$, distance between the plumb line from the centroid of $\mathrm{C} 2$ and the posterior-superior corner of $\mathrm{C} 7$. 


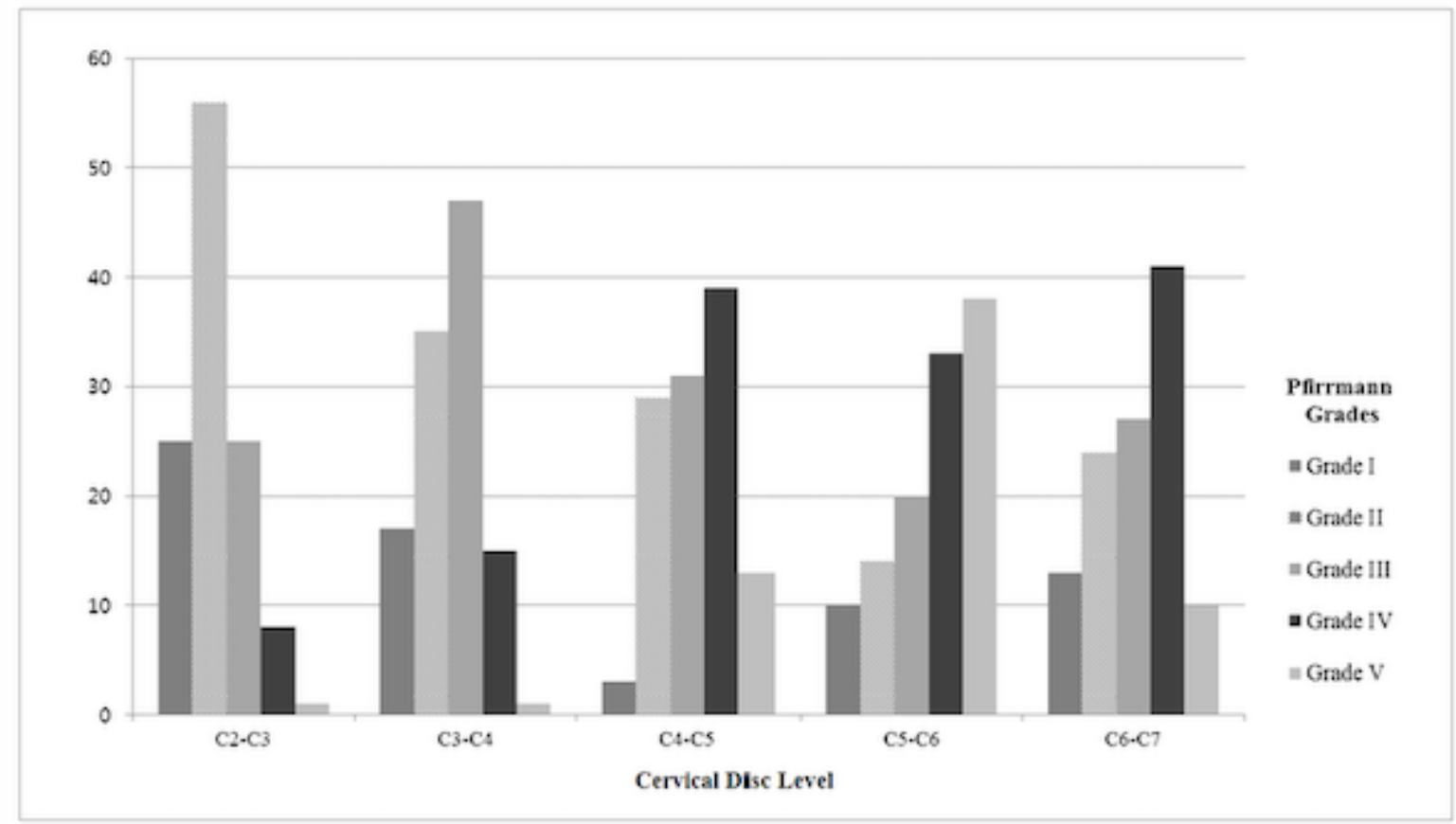

Figure 2

Number of patients with cervical disc degeneration assessed using Pfirrmann grades. 

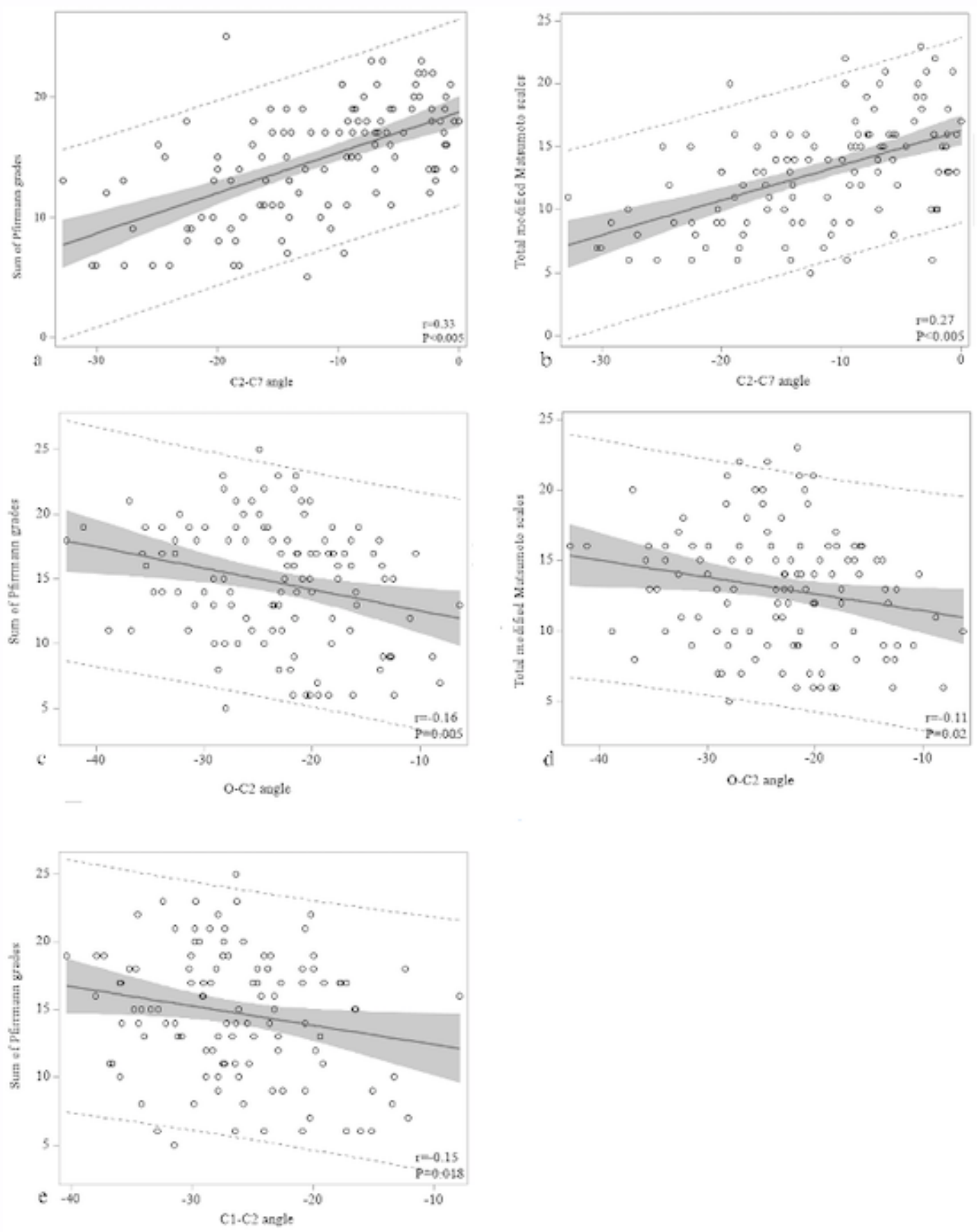

Figure 3

Correlation between sagittal angles of the cervical spine and the degree of cervical disc degeneration. 